Article

\title{
Interactive Effects in Two-Droplets Combustion of RP-3 Kerosene under Sub-Atmospheric Pressure
}

\author{
Hongtao Zhang, Zhihua Wang *D, Yong He, Jie Huang and Kefa Cen \\ State Key Laboratory of Clean Energy Utilization, Zhejiang University, Hangzhou 310027, China;

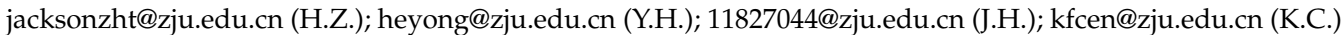 \\ * Correspondence: wangzh@zju.edu.cn; Tel.: +86-571-8795-3162
}

Citation: Zhang, H.; Wang, Z.; He, Y.; Huang, J.; Cen, K. Interactive Effects in Two-Droplets Combustion of RP-3 Kerosene under Sub-Atmospheric Pressure. Processes 2021, 9, 1229 . https://doi.org/10.3390/pr9071229

Academic Editor: Albert Ratner

Received: 20 June 2021

Accepted: 14 July 2021

Published: 16 July 2021

Publisher's Note: MDPI stays neutra with regard to jurisdictional claims in published maps and institutional affiliations.

Copyright: (c) 2021 by the authors. Licensee MDPI, Basel, Switzerland. This article is an open access article distributed under the terms and conditions of the Creative Commons Attribution (CC BY) license (https:// creativecommons.org/licenses/by/ $4.0 /)$

\begin{abstract}
To improve our understanding of the interactive effects in combustion of binary multicomponent fuel droplets at sub-atmospheric pressure, combustion experiments were conducted on two fibre-supported RP-3 kerosene droplets at pressures from 0.2 to 1.0 bar. The burning life of the interactive droplets was recorded by a high-speed camera and a mirrorless camera. The results showed that the flame propagation time from burning droplet to unburned droplet was proportional to the normalised spacing distance between droplets and the ambient pressure. Meanwhile, the maximum normalised spacing distance from which the left droplet can be ignited has been investigated under different ambient pressure. The burning rate was evaluated and found to have the same trend as the single droplet combustion, which decreased with the reduction in the pressure. For every experiment, the interactive coefficient was less than one owing to the oxygen competition, except for the experiment at $\mathrm{L} / \mathrm{D}_{0}=2.5$ and $\mathrm{P}=1.0$ bar. During the interactive combustion, puffing and microexplosion were found to have a significant impact on secondary atomization, ignition and extinction.
\end{abstract}

Keywords: kerosene droplets; high-speed cinematography; microexplosion; interactive effects; subatmospheric pressure

\section{Introduction}

A ramjet is a widely used air-breathing jet engine owing to its simple structures and high performance [1]. The stable performance height of a ramjet is below $20 \mathrm{~km}$ in the air. However, the ambient pressure at the inlet of the combustion chamber can drop rapidly to 0.1-0.3 bar with the increase in flight altitude, leading to ignition difficulties and combustion instability [2]. Therefore, exploring the combustion mechanism of the liquid fuel under low pressure is vital to improve the stability of the combustor.

In its engineering application, multicomponent fuel such as kerosene is commonly used for ramjets [3]. To better understand the physical and chemical mechanism of the multicomponent fuel combustion, several experimental and theoretical studies of the isolated fuel droplet combustion have been conducted [4-9]. A common phenomenon observed in these studies is disruption to the droplet burning process by puffing and microexplosion. Puffing is limited to a portion of the parent droplet; this fragmentation is limited and less intense, while microexplosion is the complete break-up of the droplet. It is now well understood that puffing is due to inner droplet bubble nucleation, growth and rupture of the fuel droplet under superheating [10]. This process is capable of enhancing species mixing inside the droplet, deforming the liquid-gas interface and thus the droplet shape, and causing secondary breakup of the droplet. Puffing of the boiled vapor improves fuel vapor/air mixing and thus combustion [11]. Although RP-3 kerosene is the most widely used aviation fuel in China [12], its combustion characteristics under sub-atmospheric pressure have not been well studied.

In a practical combustor, the combustion occurs in multiple droplets in the form of a spray [13]. Thus, the investigation of interactive droplet combustion is essential to the 
spray applications. A wide variety of studies focus on the changes in the burning rate $K$ of the interacting droplets' combustion [14-17]. Xiong et al. [18] claimed that interactions between droplets slowed down the droplet heating time early in the burning life due to the oxygen competition, leading to a reduction in burning rate. Faik et al. [19] studied the combustion characteristics of two diesel-based fuel droplets and found that the burning rate of interactive droplets was higher than that of an isolated droplet, owing to the increased heat transfer rate from the sooty flame. Yoschida et al. [20] conducted experiments with droplets placed at $\mathrm{SiC}$ fibre intersections under microgravity in order to study the flame spread limit for interactive burning droplets. Furthermore, the ignition delay time is found to be reduced by increasing spacing distance [14] while the flame spread increases [21]. Shaw et al. [22] studied combustion characteristics of double droplet arrays injected into high temperature environments and found that soot generation and droplet disruption were affected by droplet stream interactions. Nevertheless, the interaction effects caused by puffing and microexplosion have not been well addressed.

In conclusion, the main objective of the present study is to explore the effects of the interaction between two RP-3 droplets during combustion at different ambient pressures and spacing distances. To meet this purpose, a high-speed camera and a mirrorless camera are used to visualize the physical droplet-droplet interaction.

\section{Materials and Methods}

Figure 1 shows a schematic model of the experimental setup. The measurements were conducted in a pressure-controlled stainless steel chamber $\left(0.091 \mathrm{~m}^{3}\right)$ with four quartz windows. The ambient gas influence on droplet combustion is neglected because of the large chamber volume compared to the droplet size. A $1.45 \pm 0.14 \mathrm{~mm}$ fuel droplet was produced by approximately $1.6 \pm 0.05 \mu \mathrm{L}$ liquid fuel through a micro-pipette. Due to the relatively low thermal conductivity, two $150 \mu \mathrm{m}$ ceramic fibres were used to suspend the opposite droplets. A coiled hot wire was placed below the droplet on the right for ignition and withdrawn immediately after ignition by an air cylinder. The ignition time before retraction was precisely controlled by a time delay relay with an accuracy of $0.01 \mathrm{~s}$, and the current flowing through the hot wire was maintained at $3.10 \mathrm{~A}$ by a DC power supply during the ignition.

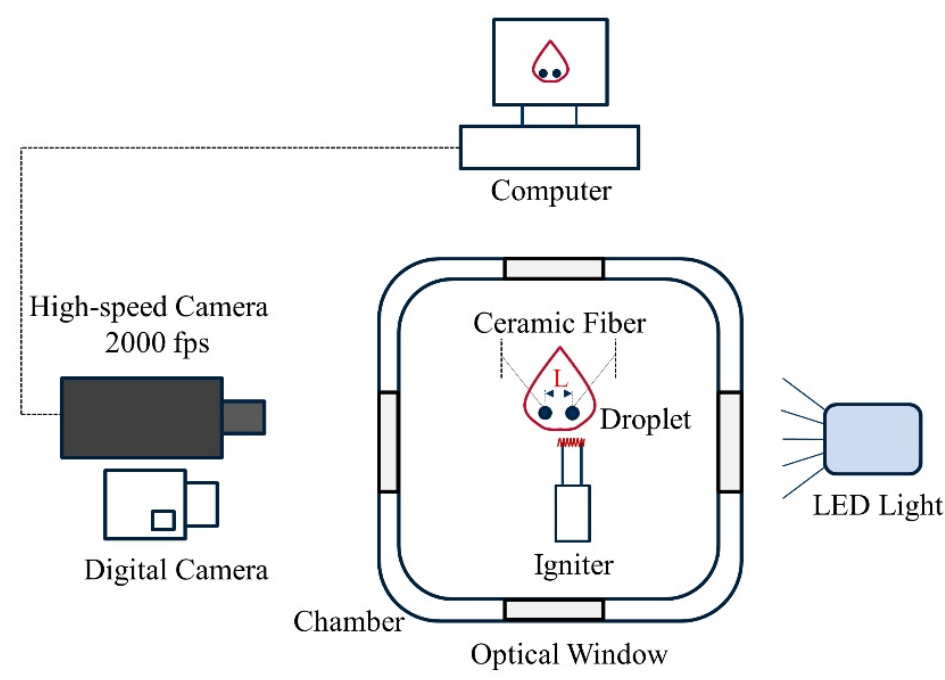

Figure 1. Schematic model of the experimental setup.

Two camera settings were used to record the burning history of binary fuel droplets. The variation in droplet diameter and phenomena of puffing and microexplosion were tracked by a black/white high-speed camera (IDT Y4-S1) at 2000 frames/s with an exposure time of $200 \mu$ s fitted with a Nikon $200 \mathrm{~mm}$ macro lens, and a high intensity LED illuminator was installed behind the droplets to provide enough light. The second setting was used for 
tracking the surrounding flame of the droplets and, for this reason, a mirrorless camera (Nikon Z5) equipped with a Sigma $105 \mathrm{~mm}$ macro lens was used to record the combustion cycle at 60 frames/s, while the LED light source was switched off.

The images were processed by self-coded Matlab algorithms. As the droplet was not spherical due to gravity and puffing, the droplet diameter was evaluated by $\pi \mathrm{D}^{2} / 4=\mathrm{A}$, where $\mathrm{A}$ is the droplet area extracted from the images, and $\mathrm{D}$ is the droplet diameter.

Chinese RP-3 kerosene was used as the fuel for all the experiments, which consisted of alkanes, naphthenes and aromatic compounds.

\section{Results and Discussion}

\subsection{Ignition and Flame Shape}

As explained previously, two RP-3 droplets were supported by two ceramic fibres. Due to the shooting range limitation of the optical window, the range of the normalised spacing distance $\mathrm{L} / \mathrm{D}_{0}$ in the experiment varies over a span of $1-6$, and the interval is 0.5 , while $\mathrm{L}$ represents the initial distance between the two droplet centres, and $\mathrm{D}_{0}$ is the initial droplet diameter. However, due to the slight difference in the size of the suspended droplets, the uncertainty of the initial normalised spacing distance is 3\%.

In the experiment, the droplet on the right side was first ignited by an electric heating coiled wire, which was kept $1 \mathrm{~mm}$ below the droplet during ignition. The temperature of the droplet on the right was heated to ignition temperature, followed by the ignition of the fuel vapour/air mixture around the droplet. Successful ignition was marked by the occurrence of a bright area of more than $50 \%$ of maximum brightness around the droplet. As shown in Figure 2, as soon as the droplet on the right was ignited, the heating wire was rapidly withdrawn and powered off. The temperature of the unburned droplet on the left was also rapidly increased by the thermal radiation and thermal convection of the flame on the right, until reaching the boiling point of the volatile component of the RP- 3 droplet. Following this, the fuel vapour mixed with the air around the droplet. As shown in the regions circled in red for the images at $10 \mathrm{~ms}$ and $15 \mathrm{~ms}$ in Figure 2, the flammable mixture was ignited in the area close to the right-hand flame and the flame rapidly propagates to the surface of the left-hand droplet. As the temperature of the left-hand droplet increased, the evaporation rate was enhanced, and the size of the left-hand flame grew and merged with the right-hand flame into one flame due to the accumulation effect of the fuel vapour.

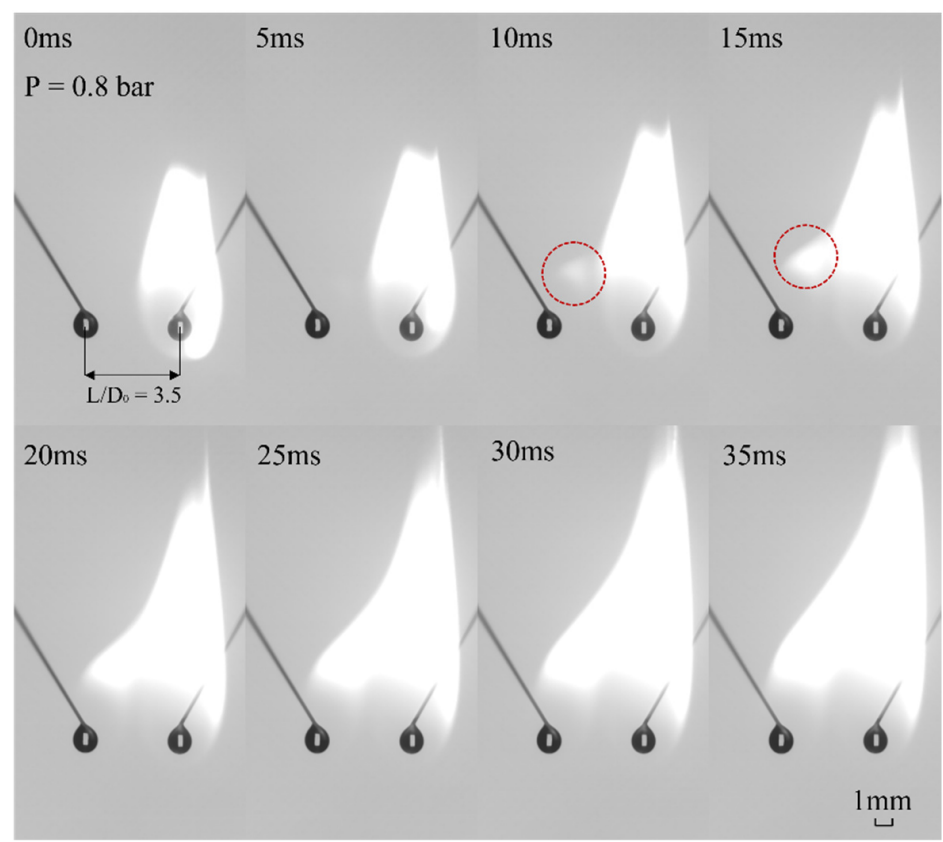

Figure 2. Temporal sequence of the flame propagation from a right burning RP-3 droplet to its neighbouring droplet $\left(\mathrm{P}=0.8\right.$ bar, $\left.\mathrm{L} / \mathrm{D}_{0}=3.5\right)$. 
The $t_{r t l}$ is the time between the ignition of the right droplet and the ignition of the left droplet. Figure 3 shows the $t_{r t l}$ at different ambient pressures and different normalised spacing distances of $1.5,2.5$ and 3.5. When $\mathrm{L} / \mathrm{D}_{0}=1.5$, the $\mathrm{t}_{\mathrm{rtl}}$ at different pressures was less than $6 \mathrm{~ms}$ because the droplets were close enough to each other that the left and right droplets ignited almost simultaneously. When $L / D_{0}=2.5$, the $t_{r t l}$ was $34 \mathrm{~ms}$ at a pressure of 1 bar, which was a significant increase compared with the previous distance condition, while the increase in $t_{r t l}$ at other pressures was much smaller. The two droplets were still ignited at the same time at 0.2 bar, which was due to the increasing flame standoff ratio of the droplets as the ambient pressure decreased. The flame front of the right-hand droplet is closer to the left droplet causing stronger radiation and convection effects [23] so that the left droplets are more likely to be ignited. When $\mathrm{L} / \mathrm{D}_{0}=3.5$, as the distance between droplets was increased further, the $t_{r t l}$ rose significantly at all pressures, which meant that the heat transferred to the left-hand droplet through radiation and convection decreased at an increasing rate. Meanwhile, the left-hand droplet at an ambient pressure of 1 bar cannot be successfully ignited by the flame of the right-hand droplet, while the left-hand droplet can still be ignited at $\mathrm{L} / \mathrm{D}_{0}=3.0$. Therefore, the maximum ignitable normalised spacing distance of the left droplet at 1 bar is 3.0.

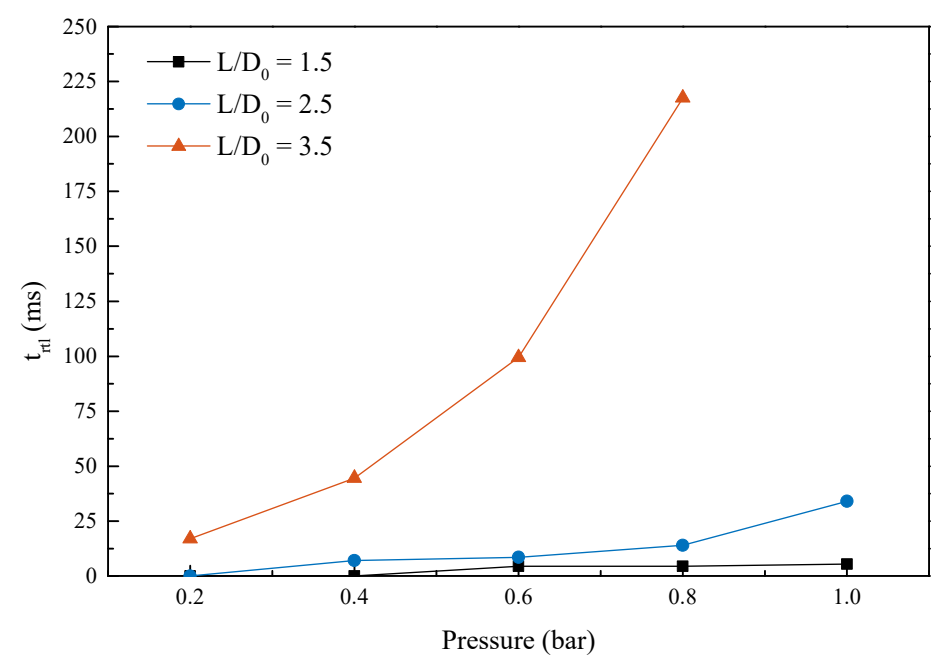

Figure 3. The flame propagation time from the right burning droplet to the left droplet at different pressures and normalised spacing distances.

The maximum ignitable normalised spacing distance for interactive droplets at different pressures is shown in Figure 4. As the flame standoff ratio of the droplet increases with decreasing ambient pressure, the maximum ignitable normalised spacing distance is found to be extended at sub-atmospheric pressure, increasing from 3.0 at 1 bar to 5.5 at 0.2 bar. However, this plot only illustrates the maximum ignitable normalised spacing distance of the droplets during steady combustion, while the ignition of the droplets could be affected by microexplosions during the combustion of the RP-3 droplets, which will be discussed later.

After the ignition of the left droplet, the evaporation rate of the droplet rapidly increased. As the evaporation rate of the droplet was greater than the consumption rate of fuel vapour in the flame, fuel vapour accumulated between the droplet surface and the flame fronts, resulting in an increased flame size. After a short time, the flame size became stable, and the left droplet flame merged with the right droplet flame to a single flame.

Figure 5 shows the two-droplet stable flame morphology at different normalised spacing distances and pressures. The binary droplets were wrapped in an enveloping flame, with a blue upstream section characterising the chemiluminescent emission from the excited $\mathrm{CH}^{*}$ radicals, and a luminous yellow flame downstream due to natural convection, which was caused by the broadband thermal radiation of the soot [24]. Similar to the combustion of an isolated droplet, as the natural convection effect is diminished with the reduction in ambient pressure, the flame standoff ratio increases and the two-droplet flame 
tends to be in the shape of a sphere. At the same time, the reduction in molecular spacing at low pressure leads to a decreased probability of collisions between small molecules, thus reducing the production of macromolecular polymers. In addition, the residence time of sooty macromolecules in the oxidation zone increases at low pressure owing to the reduced buoyant convection, thus promoting their oxidation and decomposition. Therefore, the bright yellow areas of the interactive droplet's flame become dimmer as the pressure decreases.

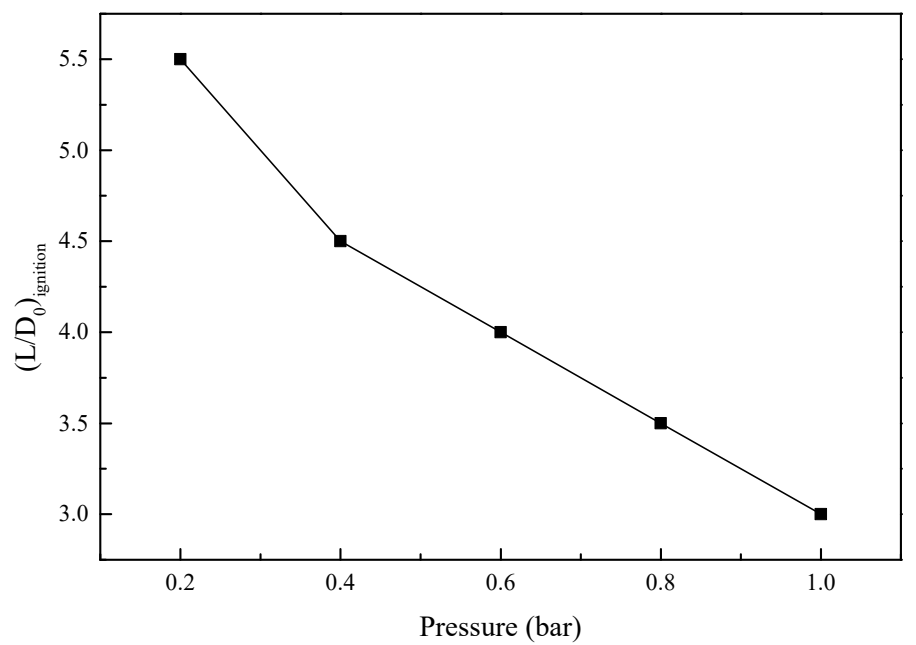

Figure 4. The maximum normalised spacing distance at which the left droplet can be ignited at different pressures.

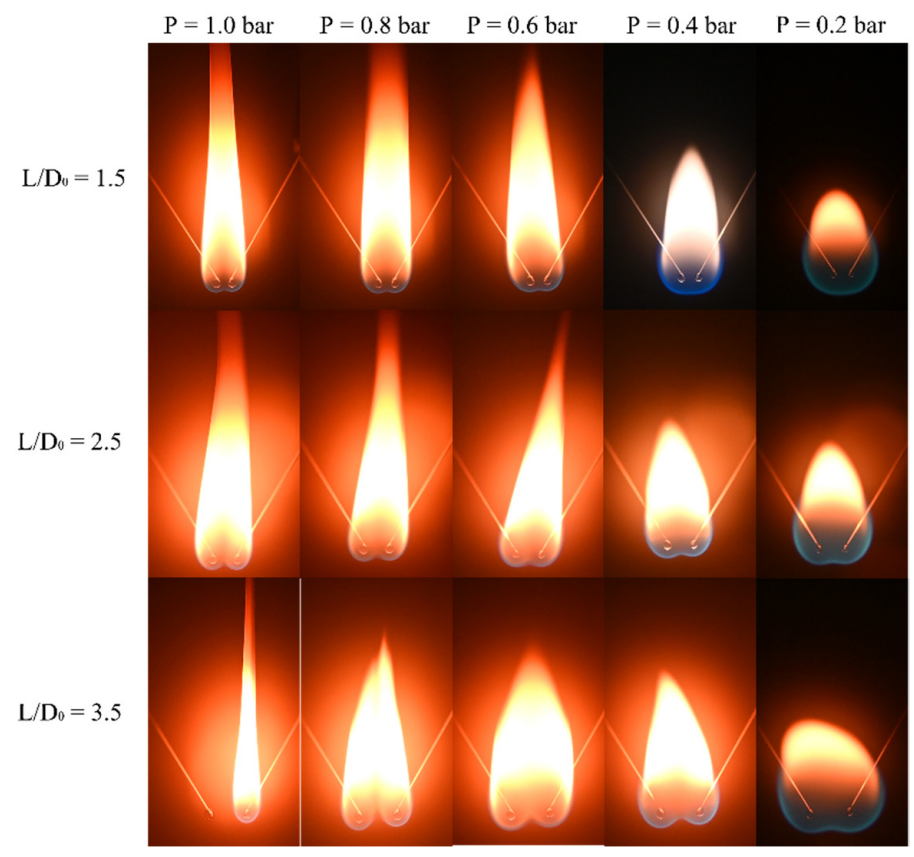

Figure 5. The interactive combustion of two RP-3 droplets at different normalised spacing distances and pressures.

As the distance between the two droplets increased, the flame around the two droplets gradually changed from a single flame to two separate flames that enveloped the respective droplets. When $\mathrm{L} / \mathrm{D}_{0}=3.5$, only the droplet on the right was ignited at 1 bar pressure and the left droplet was unable to reach the ignition temperature. At an ambient pressure of 0.8 bar, the upstream flame front of the left-hand flame and the right-hand flame separated, with only the downstream flame remaining undetached by natural convection. As the burning process proceeded, however, the droplet diameter continuously decreased and so 
did the size of the flame around the droplet; thus, the flames of the two droplets completely separated into two independent flames.

\subsection{Burning Rate}

Since RP-3 kerosene is a multicomponent fuel, more volatile components will reach the boiling point and evaporate first. As the proportion of high boiling components in the droplet gradually increases, the droplet temperature also rises gradually. At the same time, there are still volatile components left inside the droplet. Under continuous superheating, the inner droplet temperature will exceed the boiling temperatures of lower boiling point components, resulting in homogeneous nucleation inside the droplet, which leads to puffing and microexplosion.

Figure 6 shows the typical droplet diameter trends for two-droplet burnings at atmospheric and sub-atmospheric pressures. The droplet diameter at atmospheric pressure evolved relatively smoothly, approximately following $D^{2}$ law [25]. Similar to the conclusions drawn from the combustion of individual droplets, as the ambient pressure decreased, the bubble growth rate within the droplet increased, which in turn enhanced the frequency and intensity of puffing and microexplosion during droplet combustion [26]. Consequently, $\mathrm{RP}-3$ droplets at low pressures often failed to undergo a complete burning process, as shown in Figure 6, where the droplet experienced several instances of minor puffing in the middle of the burning at 0.2 bar, which did not have a noticeable effect on combustion. However, before the end of the droplet burn, the droplet underwent a severe microexplosion and the droplet diameter plummeted as a result.

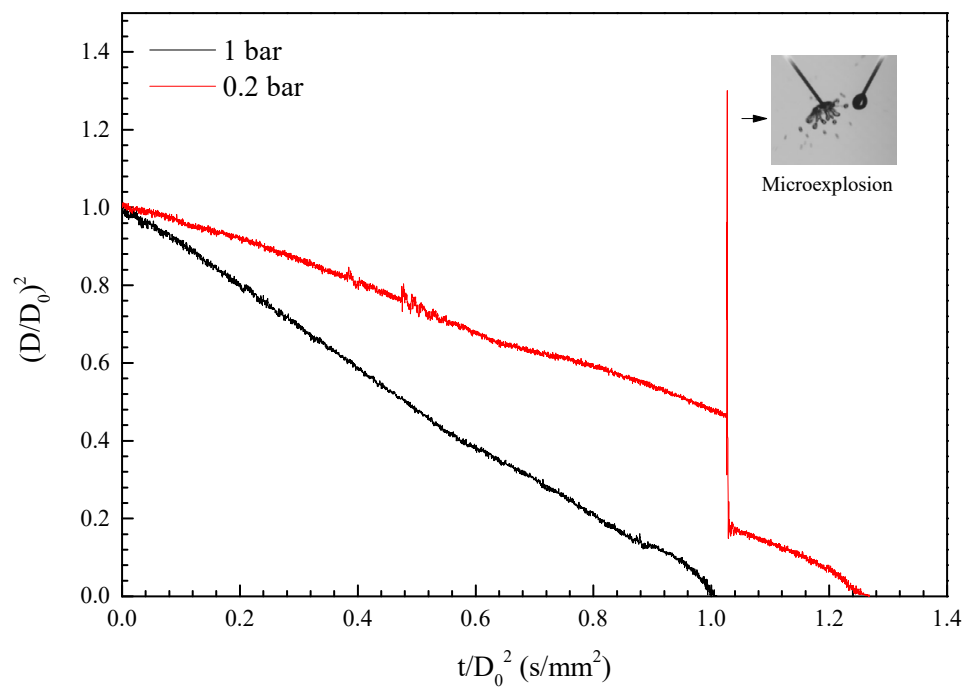

Figure 6. Typical trends for droplet diameter with time $\left(\mathrm{L} / \mathrm{D}_{0}=1.5, \mathrm{P}=1\right.$ bar and $\left.0.2 \mathrm{bar}\right)$.

In general, the droplet burning rate $K$ can be evaluated by the slope of the variation in droplet diameter, as shown in Equation (1):

$$
K=-\frac{d}{d t}\left(D^{2}\right)
$$

However, as microexplosions at low pressures lead to dramatic fluctuations in droplet diameter, accurate burning rates cannot be obtained if the entire combustion process is selected for calculation. Thus, for droplets with microexplosions in the combustion, the steady burning section prior to the microexplosion is chosen as the calculation region for the burning rate.

In two-droplet combustion, the combustion characteristics of the droplets are determined by the interaction coefficient $\eta$ [18], which is the ratio of the burning rate of binary droplets to that of an isolated droplet, as shown in Equation (2): 


$$
\eta=K_{I} / K_{S}
$$

where $K_{I}$ is the burning rate of the interacting droplets and $K_{S}$ is the burning rate of the single droplet.

Figure 7 shows the burning rates and the interaction coefficients of the two-droplet burning at different pressures for normalised spacing distances of 1.5 to 3.5. The experiment was repeated three times for each condition, and the standard deviation (STD) was calculated from the burning rate of six droplets. Thus, the uncertainty is equal to STD $/ \mathrm{K}_{\text {average }}$. Uncertainty of the burning rate was less than $6.8 \%$ in all tests. In general, the burning rate of the droplets was found to be reduced as the ambient pressure decreased, which was similar to the burning of isolated droplets. When $\mathrm{L} / \mathrm{D}_{0}=1.5$, the oxygen competition between droplets appeared to be the strongest, resulting in the most drastic decrease in combustion rate compared to single droplet combustion rates. Furthermore, as the pressure was reduced, the effect of oxygen competition on the combustion rate became more significant, with $\eta$ decreasing from 0.90 at 1 bar to 0.56 at 0.2 bar. This can be explained by the fact that as the ambient pressure decreases, the number of $\mathrm{O}_{2}$ molecules per unit volume becomes lower and, therefore, the probability of collisions between RP-3 kerosene and $\mathrm{O}_{2}$ molecules can be significantly affected any subtle local fluctuations in oxygen concentration, due to the oxygen competition effect. In this case, the burning rate of the droplets would be reduced. As the spacing distance between the two droplets was enlarged, the burning rate of the droplets showed an observable increase due to the weakening of the oxygen competition effect, but was generally lower than the burning rate of a single droplet.

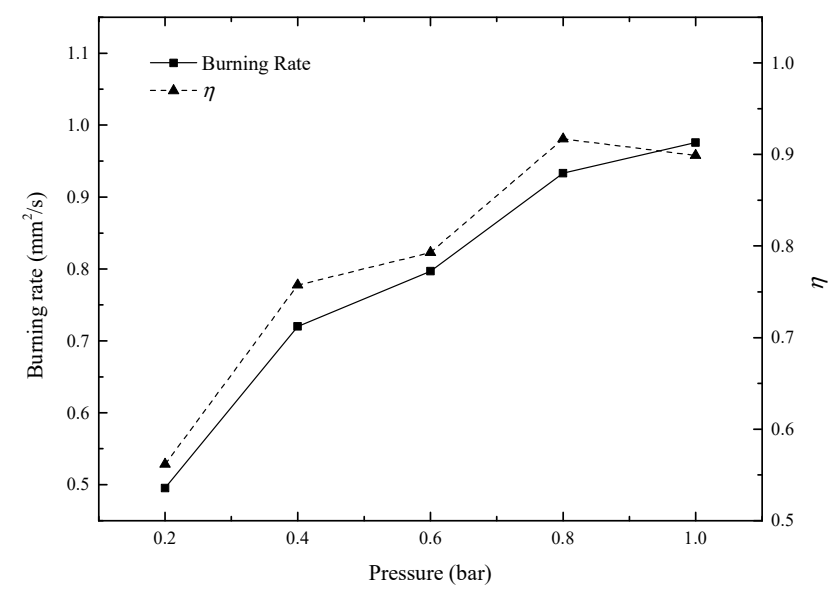

(a)

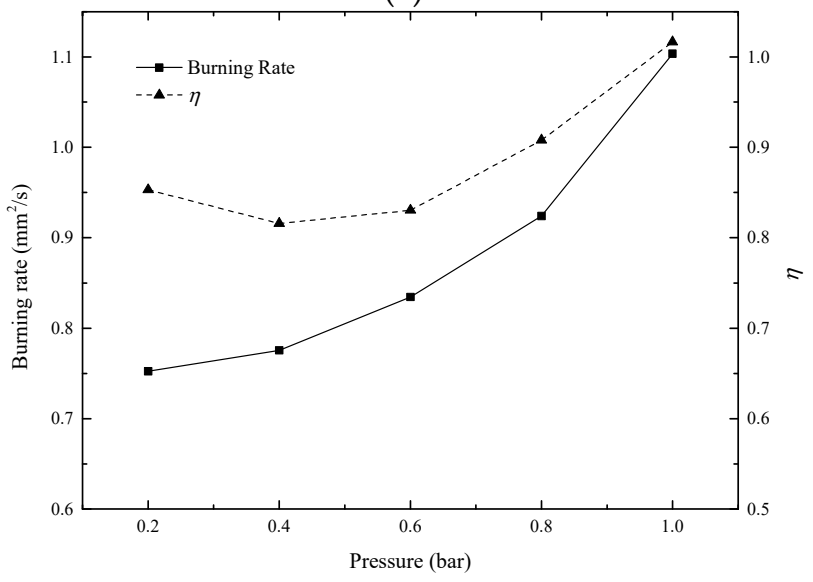

(c)

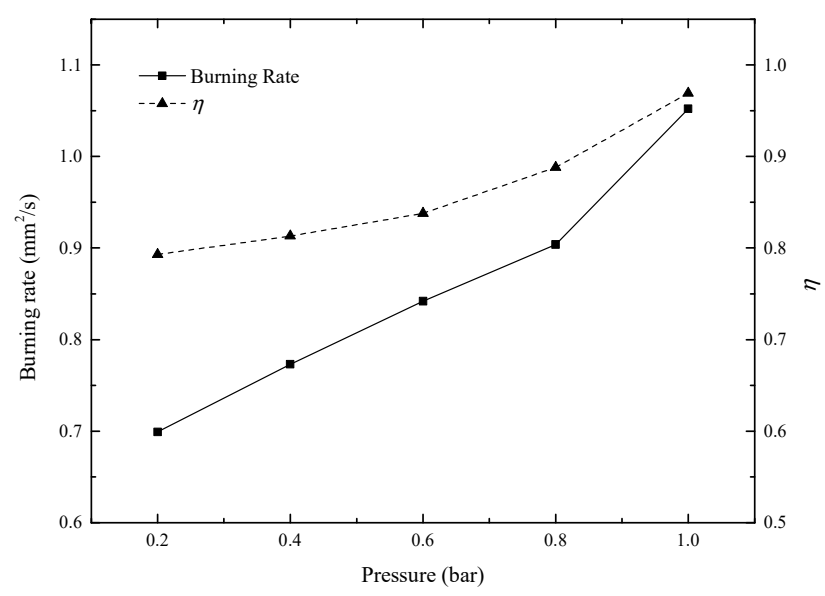

(b)

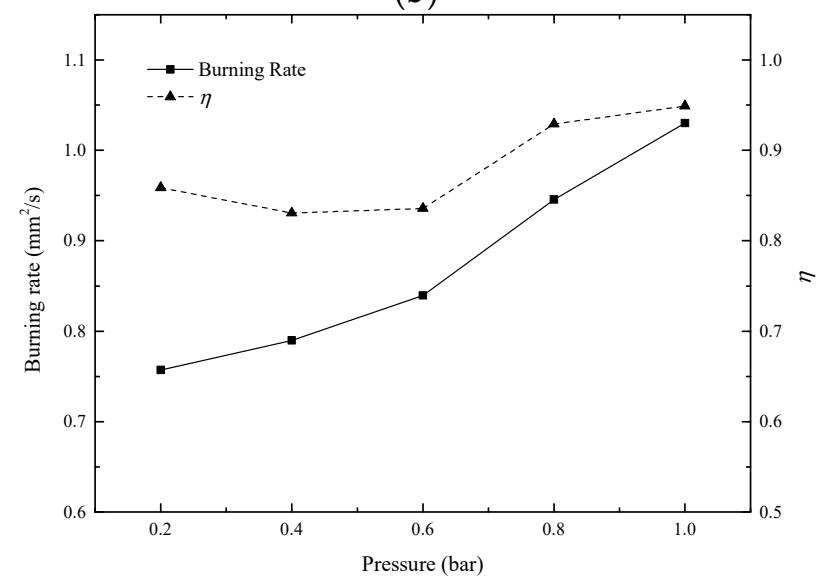

(d)

Figure 7. Cont. 


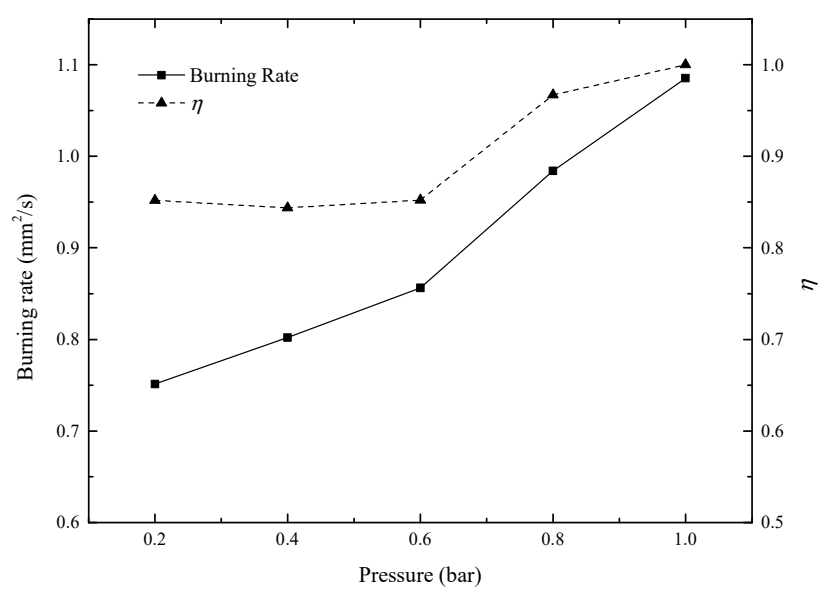

(e)

Figure 7. The effect of the normalised spacing distance and pressure on the average burning rate and interaction coefficient $(\eta)$ of the interactive droplets. (a) $\mathrm{L} / \mathrm{D}_{0}=1.5 ;(\mathbf{b}) \mathrm{L} / \mathrm{D}_{0}=2.0 ;(\mathbf{c}) \mathrm{L} / \mathrm{D}_{0}=2.5 ;(\mathbf{d}) \mathrm{L} / \mathrm{D}_{0}=3.0 ;(\mathbf{e}) \mathrm{L} / \mathrm{D}_{0}=3.5$.

It is worth noting that when $\mathrm{L} / \mathrm{D}_{0}=2.5$ and $\mathrm{P}=1 \mathrm{bar}$, the droplet interaction coefficient was larger than 1 , indicating that the two-droplet burning rate was more rapid than that of the isolated droplet. The explanation for this observation is twofold: on the one hand the oxygen competition effect had less effect on the burning rate of the droplets at atmospheric pressure, and on the other hand, the area of the downstream sooty flame had increased in the two-droplet burning compared to the single-droplet case, thus increasing the heat transfer to the droplet surface due to radiation and convection, which in turn raised the burning rate of the droplets [19]. As the normalised spacing distance of the droplets was further increased, the droplets were wrapped in two separate flames at $1 \mathrm{bar}$, so the burning of the binary droplets became similar to that of a single droplet, and the droplet interaction coefficient approached one.

\subsection{Effects of Puffing and Microexplosion}

For the combustion of interactive multicomponent RP-3 kerosene droplets, the droplet interaction not only affects the heat transfer between the droplets and the environment and the burning rate of the droplets, and has other effects due to the occurrence of puffing and microexplosion.

As shown in Figure 8, the droplet on the right side was triggered by the ejection of minor droplets from the adjacent droplet, which initiated its own microexplosion. The 0.0-2.0 ms images demonstrate the puffing of the left droplet, which expands to eject the secondary droplet, while the $2.5 \mathrm{~ms}$ and $3.0 \mathrm{~ms}$ images show the leap of the secondary droplet from the left to the surface of the right droplet, which is circled in red in the figure. As the secondary droplet contacted the right droplet and perturbed it, as shown in the 3.5-5.5 ms images, the right droplet nucleated and bubbled at the contact point of the secondary droplet, leading to a violent microexplosion. Compared to the burning of a single droplet, this phenomenon promotes secondary atomization during droplet combustion. As the spacing distance of droplets was increased, the probability that a secondary droplet, generated by the puffing or microexplosion of one droplet, could reach an adjacent droplet was reduced, and this phenomenon only occurred in those experiments under $\mathrm{L} / \mathrm{D}_{0}<3.5$.

The maximum ignitable normalised spacing distances of droplets at different pressures have been discussed in the previous section, but the previous conclusions were limited to stable combustion conditions. As shown in Figure 9, the puffing and microexplosion during droplet combustion affected the ignition of the neighbouring droplet. In accordance with previous conclusions, the maximum ignitable normalised spacing distance of the droplets at 0.8 bar is 3.5 , while the initial normalised spacing distance between the two droplets in the figure is 4.0. It can be observed that, at $0.0 \mathrm{~ms}$, the right droplet was already 
at the end of the combustion and the left droplet had not yet been ignited, which concurs with previous results. However, the right droplet started to expand and emit fuel vapour at $1.5 \mathrm{~ms}$, which in turn disturbed the flame around the droplets at the subsequent time period. In the 4.5-8.5 ms images, the flame front of the right droplet was approaching the left droplet. As a result, the heat absorbed by the left droplet due to radiation and convection rose abruptly. The temperature of the left-hand droplet was rapidly raised and reached the boiling point of the volatile component of RP-3 kerosene, then the mixture of fuel vapour and air was ignited close to the right flame. Hence, the maximum ignitable normalised spacing distance of the left-hand droplet could be extended by puffing and microexplosion. However, due to the uncertainty of puffing and microexplosion occurrences, the extended maximum ignitable normalised spacing distance cannot be evaluated precisely.

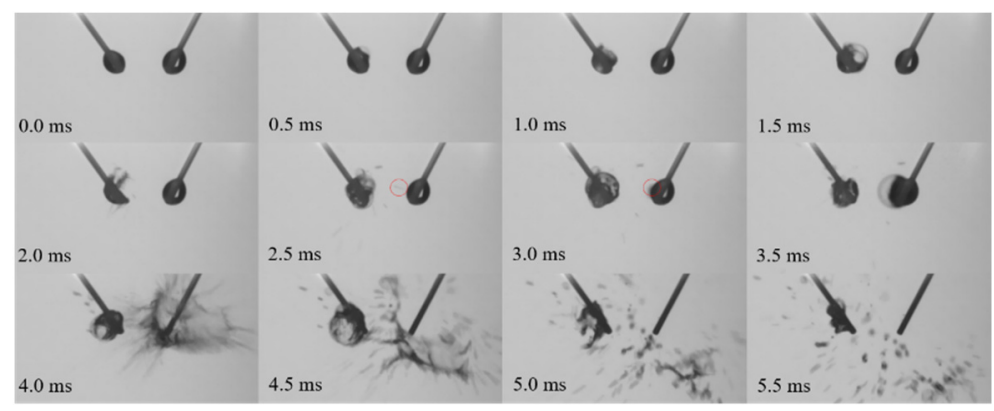

Figure 8. Temporal sequence of the RP-3 droplet microexplosion caused by a neighbouring droplet $\left(\mathrm{P}=0.4\right.$ bar, $\left.\mathrm{L} / \mathrm{D}_{0}=1.5\right)$.

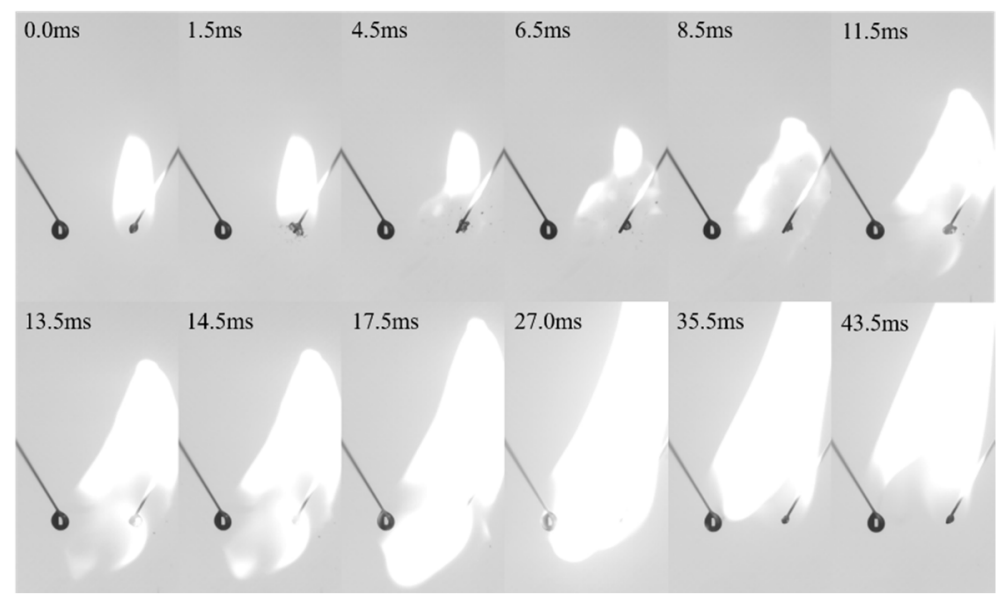

Figure 9. Temporal sequence of the effect of droplet puffing on the ignition of the neighbouring $\operatorname{droplet}\left(\mathrm{P}=0.8\right.$ bar, $\left.\mathrm{L} / \mathrm{D}_{0}=4.0\right)$.

In contrast to the ignition process, microexplosion also influences the extinction of droplets at low pressures. Figure 10 shows the extinction of a two-droplet burn at $\mathrm{P}=0.2$ bar and $\mathrm{L} / \mathrm{D}_{0}=1.5$ due to the microexplosion of the right droplet. The image at $0.0 \mathrm{~ms}$ shows that the two droplets were experiencing a steady burning. However, at $1.0 \mathrm{~ms}$ there was an intense microexplosion of the right droplet, which produced multiple secondary droplets. Due to the intensity of the microexplosion, the right-hand main droplet fell off the support fibre. As can be observed in the images at $12.0 \mathrm{~ms}$ and $15.5 \mathrm{~ms}$. The internal nucleation and puffing of the main droplet on the right was observed in a falling unsupported environment, which was circled in red. The 8.0-15.5 ms images show the downstream flame gradually moving away from the left droplet as the ejection of secondary droplets affected the stability of the combustion. Therefore, the quasi-steady combustion of the droplet on the left could not be maintained due to insufficient radiative heat transfer, which in turn resulted in the extinction. This phenomenon only occurred at an ambient 
pressure of $0.2 \mathrm{bar}$, as the oxygen competition had a significant influence on the burning rate of the interactive droplets at low pressure, where the stable burning of the droplets could be easily interrupted by the disturbance of the flame.

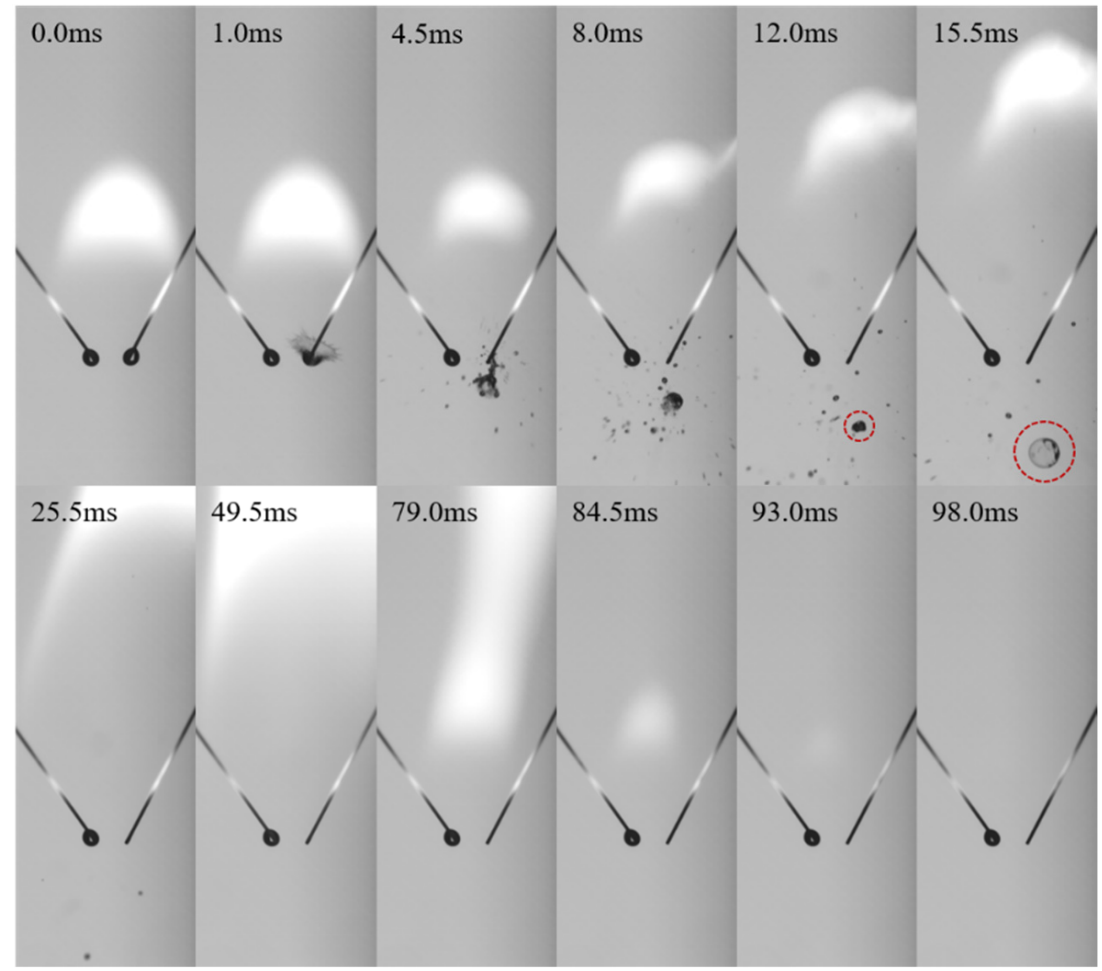

Figure 10. Temporal sequence of the flame extinction caused by the microexplosion $(\mathrm{P}=0.2 \mathrm{bar}$, $\left.\mathrm{L} / \mathrm{D}_{0}=1.5\right)$.

\section{Conclusions}

In the present work, the interactive effects in two- RP-3 kerosene droplets combustion were investigated and compared at different normalised spacing distances and subatmospheric pressures. Back-lighted high-speed cinematography has been implemented in this work. The following main conclusion can be drawn from the above discussion:

1. In a stabilised two-droplets system, the flame propagation time from the right burning droplet to the left droplet elongated exponentially with the increase of the ambient pressure and normalised spacing distance. The maximum normalised spacing distance at which the left droplet could be ignited was extended from 3.0 to 5.5 for an ambient pressure decrease from 1 bar to 0.2 bar, respectively.

2. Much like the burning of the single droplet, the reduction in ambient pressure enhanced the possibility and intensity of puffing and microexplosion during the burning. In general, compared to the corresponding isolated RP-3 kerosene droplet, the burning rate of the interacting droplets was reduced, owing to the oxygen competition between the droplets. However, the interactive coefficient $\eta$ exceeded one when $\mathrm{L} / \mathrm{D}_{0}=2.5$ and $\mathrm{P}=1$ bar. This is attributed to the increase in heat transferred from the sooty flame.

3. During the burning of binary droplets, the secondary atomization could be affected by puffing and microexplosion from its neighbouring droplet. Puffing and microexplosion of the right droplet can also extend the limit of the maximum normalised spacing distance at which the left droplet can be ignited. Meanwhile, the extinction of the two-droplets' burning was caused by the severe microexplosion that occurred when $\mathrm{P}=0.2$ bar. 
Author Contributions: Conceptualization, H.Z. and J.H.; methodology, H.Z.; software, H.Z.; investigation, H.Z.; data curation, H.Z.; writing—original draft preparation, H.Z.; writing-review and editing, Y.H. and Z.W.; supervision, Z.W.; project administration, K.C.; funding acquisition, Z.W. All authors have read and agreed to the published version of the manuscript.

Funding: This research was funded by Zhejiang Provincial Natural Science Foundation (LGC19E06001) and the Fundamental Research Funds for the Central Universities (2021FZZX001-11).

Institutional Review Board Statement: Not applicable.

Informed Consent Statement: Not applicable.

Data Availability Statement: Not applicable.

Conflicts of Interest: The authors declare no conflict of interest.

\section{References}

1. Inamura, T.; Takahashi, M.; Kumakawa, A. Combustion Characteristics of a Liquid-Fueled Ramjet Combustor. J. Propuls. Power 2001, 17, 860-868. [CrossRef]

2. Luo, W.L.; Pan, Y.; Tan, J.G.; Wang, Z.G. Experimental investigation on combustion efficiency of the ramjet model at low pressure. J. Propuls. Technol. 2010, 31, 270-275.

3. Dagaut, P.; Cathonnet, M. The ignition, oxidation, and combustion of kerosene: A review of experimental and kinetic modeling. Prog. Energy Combust. Sci. 2006, 32, 48-92. [CrossRef]

4. Law, C.K. Theory of thermal ignition in fuel droplet burning. Combust. Flame 1978, 31, 285-296. [CrossRef]

5. Farouk, T.I.; Liu, Y.C.; Savas, A.J.; Avedisian, C.T.; Dryer, F.L. Sub-millimeter sized methyl butanoate droplet combustion: Microgravity experiments and detailed numerical modeling. Proc. Combust. Inst. 2013, 34, 1609-1616. [CrossRef]

6. Ambekar, A.; Chowdhury, A.; Challa, S.; Radhakrishna, D. Droplet combustion studies of hydrocarbon-monopropellant blends. Fuel 2014, 115, 697-705. [CrossRef]

7. Shinjo, J.; Xia, J.; Ganippa, L.C.; Megaritis, A. Physics of puffing and microexplosion of emulsion fuel droplets. Phys. Fluids 2014, 26, 103302. [CrossRef]

8. Wang, C.-H.; Liu, X.Q.; Law, C.K. Combustion and microexplosion of freely falling multicomponent droplets. Combust. Flame 1984, 56, 175-197. [CrossRef]

9. Mura, E.; Calabria, R.; Califano, V.; Massoli, P.; Bellettre, J. Emulsion droplet micro-explosion: Analysis of two experi-mental approaches. Exp. Therm. Fluid. Sci. 2014, 56, 69-74. [CrossRef]

10. Avulapati, M.M.; Ganippa, L.C.; Xia, J.; Megaritis, A. Puffing and micro-explosion of diesel-biodiesel-ethanol blends. Fuel 2016, 166, 59-66. [CrossRef]

11. Hoxie, A.; Schoo, R.; Braden, J. Microexplosive combustion behavior of blended soybean oil and butanol droplets. Fuel 2014, 120, 22-29. [CrossRef]

12. Liu, Y.; Liu, Y.; Chen, D.; Fang, W.; Li, J.; Yan, Y. A Simplified Mechanistic Model of Three-Component Surrogate Fuels for RP-3 Aviation Kerosene. Energy Fuels 2018, 32, 9949-9960. [CrossRef]

13. Mikami, M.; Kono, M.; Sato, J.I.; Dietrich, D.L. Interactive effects in two-droplet combustion of miscible binary fuels at high pressure. Symp. (Int.) Combust. 1998, 27, 2643-2649. [CrossRef]

14. Sangiovanni, J.J.; Kesten, A.S. Effect of droplet interaction on ignition in monodispersed droplet streams. Symp. (Int.) Combust. 1977, 16, 577-592. [CrossRef]

15. Annamalai, K.; Ryan, W. Interactive processes in gasification and combustion. Part I: Liquid drop arrays and clouds. Progr. Energy Combust. Sci. 1992, 18, 221-295. [CrossRef]

16. Koshland, C.P.; Bowman, C.T. Combustion of monodisperse droplet clouds in a reactive environment. Symp. (Int.) Combust. 1985, 20, 1799-1807. [CrossRef]

17. Oka, K.; Tsue, M.; Kono, M.; Mikami, M.; Sato, J.; Dietrich, D.L.; Williams, F.A. Strongly interacting combustion of two mis-cible binary-fuel droplets at high pressure in microgravity. Symp. (Int.) Combust. 1998, 27, 2651-2657. [CrossRef]

18. Xiong, T.Y.; Law, C.K.; Miyasaka, K. Interactive vaporization and combustion of binary droplet systems. Symp. (Int.) Combust. 1985, 20, 1781-1787. [CrossRef]

19. Faik, A.M.-D.; Zhang, Y. Liquid-phase dynamics during the two-droplet combustion of diesel-based fuel mixtures. Exp. Therm. Fluid. Sci. 2020, 115, 110084. [CrossRef]

20. Yoshida, Y.; Iwai, K.; Nagata, K.; Seo, T.; Mikami, M.; Moriue, O.; Sakashita, T.; Kikuchi, M.; Suzuki, T.; Nokura, M. Flame-spread limit from interactive burning droplets in microgravity. Proc. Combust. Inst. 2019, 37, 3409-3416. [CrossRef]

21. Nomura, H.; Iwasaki, H.; Suganuma, Y.; Mikami, M.; Kikuchi, M. Microgravity experiments of flame spreading along a fuel droplet array in fuel vapor-air mixture. Proc. Combust. Inst. 2011, 33, 2013-2020. [CrossRef]

22. Shaw, B.D.; Dwyer, H.A.; Wei, J.B. Studies on Combustion of Single and Double Streams of Methanol and Metha-nol/Dodecanol Droplets. Combust. Sci. Technol. 2002, 174, 29-50. [CrossRef] 
23. Mikami, M.; Kato, H.; Sato, J.; Kono, M. Interactive combustion of two droplets in microgravity. Symp. (Int.) Combust. 1994, 25, 431-438. [CrossRef]

24. Wei, J.B.; Shaw, B.D. Reduced Gravity Combustion of Propanol Droplets in Oxygen-Inert Environments. Combust. Sci. Technol. 2009, 181, 1480-1494. [CrossRef]

25. Law, C.K.; Law, H.K. A d2-Law for Multicomponent Droplet Vaporization and Combustion. AIAA J. 1982, 20, 522-527. [CrossRef]

26. Zhang, H.; Wang, Z.; He, Y.; Xia, J.; Zhang, J.; Zhao, H.; Cen, K. Ignition, puffing and sooting characteristics of kerosene droplet combustion under sub-atmospheric pressure. Fuel 2021, 285, 119182. [CrossRef] 